Iranian Journal of Pathology | ISSN: 2345-3656

\title{
Role of FGFR3 in Urothelial Carcinoma
}

\author{
Malik Akanksha ${ }^{1}$, Sundaram Sandhya ${ }^{2 *}$ \\ 1. Post graduate, Sri Ramachandra Medical College and Research Institute, Porur, Chennai, India \\ 2. Professor, Department of Pathology, Sri Ramachandra Medical College and Research Institute, Porur, \\ Chennai, India
}

\begin{tabular}{cl}
\hline KEYWORDS & ABSTRACT \\
\cline { 1 - 2 } $\begin{array}{c}\text { FGFR3 Protein, } \\
\text { Urothelial carcinoma, }\end{array}$ & $\begin{array}{l}\text { Background and Objective: This study was undertaken to analyze the } \\
\text { carcinoma and correlate its expression with the pathological stage, recurrence and other } \\
\text { clinicopathological parameters. }\end{array}$
\end{tabular}

Carcinoma, Transitional Cell,

Bladder cancer

Material and Methods: A retrospective study was undertaken on paraffin blocks of 55consecutiveurothelial carcinoma specimens in 28 months received in Sri Ramachandra Medical College, Chennai, India. Blocks with the sections containing the tumor and adjacent normal epithelium were chosen for the immunohistochemical (IHC) study of FGFR3.

Results: IHC expression of FGFR3 in high grade (HG) invasive urothelial carcinoma was positive in $18 \%$ cases, $66.7 \%$ of HG non-invasive urothelial and $82.6 \%$ of low grade (LG) non-invasive urothelial carcinomas.

Article Info

The FGFR3 expression was presented in $78.1 \%$ of non-invasive carcinoma. In case of invasive urothelial carcinoma, the FGFR3 positivity was observed in $18.2 \%$ of tumors $(P<0.05)$

FGFR3 expression in LG tumors was positive in $82.6 \%$ of the cases whereas $32.3 \%$ of HG cases were positive for FGFR3 $(P<0.05)$.

FGFR3 was expressed in $14.3 \%$ of HG invasive tumors which recurred. HG non-invasive

Received 02 Oct 2018;

Accepted 09 Mar 2019;

Published Online 10 Jun 2019;

DOI: $10.30699 / \mathrm{IJP} .14 .2 .148$ tumors were positive for FGFR3 in $80 \%$ of the cases. LG non-invasive tumors were positive for FGFR3 in $72.7 \%$ of cases $(P<0.05)$.

Conclusion: The expression of FGFR3 is higher in low grade, non-invasive tumors and recurrent non-invasive tumors. The targeted therapy for FGFR3 may be used as one of the modes of treatment for urothelial carcinoma. It can also be used as a marker to determine the grade in difficult cases and the risk of recurrence.

Corresponding Information:

Sundaram Sandhya, Professor, Department of Pathology, Sri Ramachandra Medical College and Research Institute, Porur, Chennai, India, Email: sandsrid@gmail.com

Copyright $\odot$ 2019, IRANIAN JOURNAL OF PATHOLOGY. This is an open-access article distributed under the terms of the Creative Commons Attributionnoncommercial 4.0 International License which permits copy and redistribute the material just in noncommercial usages, provided the original work is properly cited.

\section{Introduction}

Bladder cancer is the seventh most common malignancy worldwide, accounting for approximately $3.2 \%$ of all cancers globally. It is more often seen in males than females. An estimated of 260,000 and 76,000 new cases occur each year in men and women, respectively (1).

Urothelial carcinomas may present as papillary or flat neoplasms, majority of which are usually non-invasive. Diverse molecular pathways are implicated in the pathogenesis and development of non-invasive and invasive tumors (2).
Currently, the depth of invasion, histologic grade and margin status are the most important prognostic factors. However, several other parameters such as p53 expression, ki - 67, loss of E cadherin, CK 20 and FGFR3 mutations have been implicated as indicators of progression and recurrence of the tumor. ${ }^{1}$ Bladder tumors have a high rate of recurrence and progression, thus, prognostic outcome for urothelial carcinoma remains unpredictable, demanding validation of important markers . 
Binding of the fibroblast growth factor receptor (FGFR) to the mutated FGFR3 tyrosine kinase receptor leads to the activation of downstream pathways including RAS- MAPK, PI3K and STAT6. These pathways regulate a number of cellular functions including differentiation and division. Activation of the wild type FGFR3 may occur via ligand independent dimerization of the over-expressed protein, increased expression of ligand or via differential splicing that generates a splice variant such as FGFR3c with the altered ligand specificity (3).

FGFR3 mutations have been described in spermatocytic seminoma, multiple myeloma and cervical cancer. Some cases of multiple myeloma are seen to express both mutation and overexpression of FGFR3.

Mutations of FGFR3 are found in around 80\% of pTa tumors (2,3). FGFR3 mutations are present in $21 \%$ of pT1 and $16 \%$ of pT2-4 tumors (2).

These mutations which occur at the level of genome, are technologically difficult to detect in the routine laboratory (4), therefore, this study was conducted to analyze the immunohistochemical expression of FGFR3 in urothelial carcinoma and correlate the FGFR3 expression with the pathological stage, recurrence and other clinicopathological parameters.

\section{Materials and Methods}

This is a retrospective study on paraffin blocks of 55consecutive urothelial carcinoma specimens received in the Department of Pathology at a tertiary care centre, Sri Ramachandra Medical College, Chennai, India from January 2013 to May 2015. The paraffin blocks were made on samples from tumor areas along with the adjacent normal areas from the specimens received in the department.

Permission of the institutional ethics committee was obtained prior to commencing the study. Gross findings were recorded and clinical data of the patients including patient age, gender, metastatic status, cystoscopy findings, prognosis and outcome along with the important physiological parameters were obtained from the medical record section and local area computer network service.
The Haematoxylin and Eosin (H\&E) stained slides were reviewed by two pathologists and the diagnosis was made as per the WHO 2016 criteria of urothelial tumors.

The staging was done in accordance with the TNM AJCC $8^{\text {th }}$ edition into pTa, pT1 and pT2 tumors.

\section{Inclusion criteria}

Microscopically proven cases of urothelial carcinomas including low grade non-invasive, high grade non-invasive, low grade invasive and high grade invasive.

\section{Exclusion criteria}

- Urothelial carcinoma arising from kidney and ureter;

- Bladder malignancies other than urothelial carcinoma.

- Recurrence was considered as cases which had visible tumor on follow up cystoscopy and were confirmed by the subsequent histopathological evaluation.

- pTa tumors (non-invading lamina propria) and pT1 tumors (invading into lamina propria) were categorized as non-muscle-invasive tumors and pT2(invading detrusor muscle) were categorized as muscle-invasive tumors due to the difference in different treatment modalities.

The non-muscle-invasive tumors were treated with chemotherapy and intravesical BCG therapy. One case of LG non-invasive urothelial carcinoma underwent radical cystectomy due to failure of BCG therapy.

The cases with muscle invasion underwent radical cystectomy, however, the patients who were found to be unfit for the surgery in this category underwent TURBT and chemoradiotherapy.

Paraffin blocks made after routine processing were cut as 3 microns sections and were stained with $\mathrm{H} \& \mathrm{E}$ for the routine morphology. Tumor grading was performed based on the architectural and cytological features.

Blocks with the section containing the tumor and adjacent normal epithelium were chosen for immunohistochemical study. This Immunohistochemical study of FGFR3 (Clone: B-9: sc 
13121, Subtype: $\operatorname{IgG}_{2 \mathrm{a}}$, Source: mouse, Immunogen: amino acids 25-124 of FGFR3 of human origin, Santa Cruz Biotechnology, USA) was conducted on the estimated sample size of 55 cases of histopathologically proven urothelial carcinoma cases. The IHC was performed on $0.1 \%$ poly-L-Lysine coated slides, which were then kept in the incubator for 30 minutes at $60^{\circ} \mathrm{C}$. The slides were placed in citrate buffer at $\mathrm{pH}$ of 6.0. Heat induced antigen retrieval was done by pressure cooker with an operating pressure of $103 \mathrm{kpa} / 115$ at $120^{\circ} \mathrm{C}$, then, blocking was done by $3 \%$ hydrogen peroxide. The antibody was used in a dilution of 1:50 and incubated overnight.

Previous studies have shown that the human epidermal cells were strongly positive for FGFR3, which was interpreted as positive control ${ }^{5}$.

As negative control, the slide was treated by replacement of primary antibody with nonimmune serum (28).

All the slides were examined and scored according to the Q score.

Q score (6):

A semi-quantitative scoring system was adopted: 0 , all tumor cells negative; 1 , faint but detectable positivity in some or all cells; 2 , weak but extensive positivity; 3 , strong positivity. Percentage staining score was graded as 0 to 4 .

$\mathrm{Q}$ score $=$ intensity $\times$ percentage staining

$Q$ score of 0 and 1 were taken as negative result and 2 to 12 as positive result.

FGFR3 expression was observed in the cytoplasm and nucleus ${ }^{4}$. However only one case of low grade non-invasive carcinoma showed nuclear positivity, which was an exception in our study, therefore it was not included in the statistical analysis.

The statistical analysis was done on the data collected using the "SPSS Version 11" statistical program. Pearson Chi-square test was used to determine significant clinicopathological differences between FGFR3 expression in positive and negative tumors. Differences were considered statistically significant when P-value was $<0.05$.

\section{Results}

Patients' characteristics, treatment and recurrence

The study comprised of 55 patients, of whom low grade non-invasive tumors were diagnosed in $24(43.6 \%)$ ones. However, in our study no low grade invasive tumor was found. High grade invasive tumors accounted for $22(40 \%)$ of all the cases, whereas high grade non-invasive were found to be 9 (16.4\%).

The patients were followed up for 5 to 36 months, mean follow-up period was 24 months. In our study, eight HG invasive and one LG noninvasive tumors underwent radical cystectomy. Of the remaining 46 cases, $93.3 \%$ (14/15) HG invasive recurred. Amongst HG non-invasive cases, $62.5 \%$ (5/8) recurred. The recurrence was documented in $47.8 \%(11 / 23)$ of LG non-invasive tumors.

\section{FGFR3 expression}

IHC expression of FGFR3 antibody in $\mathrm{HG}$ invasive urothelial carcinoma was positive in $18 \%$ (4/22) cases. The Q score in HG invasive tumors ranged from 0 to 4 , average was $0.72 \pm 1.20$.

In HG non-invasive urothelial carcinomas the positivity was seen in $66.7 \%$ (6/9) of cases. High grade non-invasive tumors had a range of $\mathrm{Q}$ score from 1 to 6 , with an average of $3.11 \pm 1.76$.

The highest positivity was seen in LG noninvasive urothelial carcinoma $82.6 \%(19 / 23)$ of tumors. LG non-invasive tumors had a $\mathrm{Q}$ score ranging from 1 to 12 with an average of $5.86 \pm$ 4.28. One case of LG non-invasive urothelial carcinoma had nuclear positivity for FGFR3.

\section{FGFR3 expression with grade and stage}

In non-invasive carcinoma FGFR3 expression was present in $78.1 \%(25 / 32)$ whereas, it was negative in $21.9 \%$ (7) of the tumors.

In case of invasive urothelial carcinoma FGFR3 positivity was observed in $18.2 \%$ (4/22) of tumors, while 18 or $81.8 \%$ were negative.

The $\mathrm{P}$-value was significant $(P<0.05)$.

FGFR3 expression in low grade tumors was positive in $82.6 \%(19 / 23)$ and negative in $17.4 \%$ (4/23) of the cases. And $67.7 \%$ (21/31) of high grade tumor cases were found to be negative 
whereas $32.3 \%$ (10/31) were positive for FGFR3. The $\mathrm{P}$-value was found to be significant $(P<0.05)$

\section{FGFR3 expression in recurred cases}

FGFR3 was expressed in $14.3 \%$ (2/14) of HG invasive tumors which recurred. In this category $85.7 \%$ of the cases were negative. HG non- invasive tumors were positive in $80 \%$ (4/5) of the cases, whereas $20 \%$ were negative for FGFR3.

LG non-invasive tumors were positive for FGFR3 in $72.7 \%(8 / 11)$ of the cases, whereas $27.3 \%$ (3/11) were negative.

This was significant with a P-value of $<0.05$.

Table 1. Patient details

\begin{tabular}{cc}
\hline Age at diagnosis & $\mathbf{1 9 - 8 7}$ years \\
Mean age & 61.5 years \\
\hline Highest incidence & $60-69$ years \\
\hline Male : female & $4: 1$ \\
\hline Cigarette smoking & $30(54.5 \%)$ \\
\hline Hematuria & $46(86.6 \%)$ \\
\hline Urinary tract infection & $26(47.3 \%)$ \\
\hline Pain & $30(54.5 \%)$ \\
\hline Cystoscopy findings & $20(36.4 \%)$ \\
\hline Single & $35(63.6 \%)$ \\
\hline Multiple & 24 \\
\hline Histopathological diagnosis & 0 \\
\hline Low grade non-invasive urothelial carcinoma & 9 \\
\hline High grade non-invasive urothelial carcinoma & 22 \\
\hline
\end{tabular}

Table 2. FGFR3 positivity with grade and stage

\begin{tabular}{|c|c|c|c|c|c|c|c|c|c|}
\hline & $\begin{array}{l}\text { LG non- } \\
\text { inv UCA }\end{array}$ & $\begin{array}{l}\text { HG non- } \\
\text { inv UCA }\end{array}$ & $\begin{array}{c}\text { HG inv } \\
\text { UCA }\end{array}$ & $\begin{array}{c}\text { Low } \\
\text { grade } \\
\text { UCA }\end{array}$ & $\begin{array}{c}\text { High } \\
\text { grade } \\
\text { UCA }\end{array}$ & P-value & $\begin{array}{l}\text { Non- } \\
\text { inv } \\
\text { UCA }\end{array}$ & Inv UCA & P-value \\
\hline $\begin{array}{c}\text { FGFR3 } \\
\text { positivity }\end{array}$ & $\begin{array}{c}19 / 23 \\
(82.6 \%)\end{array}$ & $\begin{array}{c}6 / 9 \\
(66.7 \%)\end{array}$ & $\begin{array}{c}4 / 22 \\
(18 \%)\end{array}$ & $\begin{array}{c}19 / 23 \\
(82.6 \%)\end{array}$ & $\begin{array}{c}10 / 31 \\
(32.3 \%)\end{array}$ & $<0.05$ & $\begin{array}{l}25 / 32 \\
(78.1)\end{array}$ & $\begin{array}{c}4 / 22 \\
(18.2 \%)\end{array}$ & $<0.05$ \\
\hline
\end{tabular}

Table 3. FGFR3 positivity in recurred cases

\begin{tabular}{ccccc} 
& LG non-inv UCA & HG non-inv & HG-inv UCA & P-value \\
\hline \multirow{2}{*}{ FGFR3 positivity } & $8 / 11$ & $4 / 5$ & $2 / 14$ & $<0.05$ \\
\hline
\end{tabular}

LG non-inv UCA: low grade non-invasive urothelial carcinoma HG non-inv UCA: high grade non-invasive urothelial carcinoma UCA : urothelial carcinoma 


\section{Discussion}

In our study on56 patients, the male to female ratio was $4: 1$, which corresponded to the studies done before $(7,8)$. The mean age was 61.5 which was in concordance with a large study done on the Indian population comprising of 561 patients, in which the mean age was 60.5(11). In our study, the youngest patient had19 years old and presented with LG non-invasive urothelial carcinoma with no recurrence. In young patients there is higher frequency of low grade tumors, and the disease at the time of diagnosis is more frequently at a low stage $^{9}$. In a study conducted on 45 patients younger than 30 years Huang et al., observed that patients aged 25 years or younger were less likely to experience tumor recurrence and expressed more proportion of the negative pattern of FGFR3 protein (10). In the current study the patient did not have a recurrence and expressed low level of FGFR3, with a Q score of 2.

The history of smoking was present in $54.2 \%$ of cases. The risk of bladder cancer is 2-6 times in smokers than in no- smokers. In two Indian population-based studies the incidence of smokers with bladder cancer were found $68.6 \%$ and $71.6 \%$ $(11,12)$. However, in our study, slight discrepancy may be due to incomplete history by non-compliant patients or a natural outcome of our study population.

Spruck et al. proposed that cigarette smoke does not significantly change the type of mutations of p53 in smokers and non-smokers; however, it makes the DNA more susceptible to damage (13).

The most common clinical presentation in our study was hematuria accounted for $86.6 \%$ of the initial symptoms. This is in agreement with the reported 80 to $85 \%$ in world literature (1).

The $54.5 \%$ patients presented with pain as a presenting complaint, while, urinary tract infection accounted for $47.3 \%$ of the clinical presentations.

As examined cystoscopically, $63.6 \%$ and $36.4 \%$ of the tumors were multiple and single, respectively. Tumor multifocality and concurrent carcinoma in situ have been identified as risk factors for the recurrence and progression (1).

The most common histological subtype was low grade non-invasive accounting for $43.6 \%$. High grade non-invasive were found to be $16.4 \%$. Hence, non-invasive tumors accounted for $58.9 \%$.

High grade invasive tumors accounted for $40 \%$ (22) of all the cases. There were no instances of low grade invasive tumors in our study.

According to a study by Gupta et al., on Indian population, $26 \%$ of the patients had muscleinvasive disease at the time of presentation while the remaining $74 \%$ had non-muscle- invasive bladder carcinoma (11).

A study by Tomilson et al., found a highly significant association between the protein expression level and mutation status. ${ }^{3} \mathrm{Here}$, in our study we compared the FGFR status with grade and stage. Young-Hee Maeng et al. reported 78.9\% of pTa tumors expressed FGFR3 by immunohistochemistry (4). Tomilson et al., on IHC reported $81 \%$ positivity in non-invasive tumors (3). In our study, $78.1 \%$ of non-invasive carcinomas expressed FGFR3shown by IHC. Gomez roman reported IHC expression of $71.4 \%$ of non-invasive tumors (14).

In a study done by Poyet et al.in 2015 a positivity of $69 \%$ for pTa tumors was reported (15).

However, Matsumoto et al., did not report any significant association between FGFR3 expression and stage of tumor (16).

In the present study there was a significant association between FGFR3 expression and the stage $(P<0.05)$.

In our study, the FGFR3 expression in high grade invasive tumors (pT2 - pT4) was found to be $18.2 \%$ of cases. This showed a significant association between the stage and FGFR3 expression with $\mathrm{P}$-value $<0.05$. Our value was in concordance with a study by Bodoor et al (17) on 130 patients who got the FGFR3 expression in 15\% of pT2 and $2 \%$ of pT3 tumors. However, they did not find any significant association between the stage and the expression level, which could be due to tumor heterogeneity.

Guancial et al., in 2015 studied 231 primary muscle-invasive tumors and found a positivity of $29 \%$ by IHC (18). On the other hand, Gomez Roman observed $49 \%$ positivity in pT2 tumors (14).

In our study, positivity and negativity for the low grade tumors was assessed to be $82.6 \%$ and 
$17.4 \%$ cases, respectively. The $81.3 \%$ of low grade tumors were positive as reported by a Korean study (4). According to the study done by Poyet et al., in the low grade tumor group, $69 \%$ of tumors were FGFR3 positive (15).

Young-HeeMaeng et al., reported $47.8 \%$ of high grade tumors to be positive for FGFR3 (4). In the present study, we found $32.3 \%$ of high grade tumors to be positive.

In an Iranian study, the authors found an increased expression of FGFR3 in most of the samples inall grades and stages (19).

The association of FGFR3 with grade was significant in our study with a P-value $<0.05$.

Non-invasive high grade tumors recur frequently in up to $70 \%$ of cases, but progression is rare $(1,20)$. High grade non-invasive tumors recur frequently and progress in up to $65 \%$ of cases (1).

The role of FGFR3 in predicting the prognosis and progression remains unclear. Mutation studies done on two groups of the same have reported an association between mutations and a higher recurrence rate (Mhawech-Fauceglia $\mathrm{P}$ et al, Van Oers et al) $(21,22,23)$, whereas others are contrary (van Rhijn BW et al, Hernández $\mathrm{S}$ et al) $(24,25)$. Few studies have been done by immunohistochemistry. Young-Hee Maeng et al. reported FGFR3 to be of prognostic value for recurrence-free survival in non-muscle-invasive tumors (4), although it was not an independent marker.

Poyet et al., in 2015 reported that patients with tumors expressing FGFR 3 confirmed by IHC had a significantly increased disease specific survival as compared to the negative expression. High grade neoplasms in their study showed a trend of better disease specific survival but it was not statistically significant (15).

On the other hand, Bodoor et al. did not find any prognostic value of FGFR3 for recurrence free survival, although it was not an independent marker (17).

Low grade non-invasive tumors which recurred were positive for FGFR3 in $72.7 \%$ of the cases. High grade non-invasive tumors were positive in $80 \%$ of the cases.

In the current study, invasive tumors which recurred were positive for FGFR3 in 14.3\% of the cases. This was found to be statistically significant $(P<0.05)$.

In the cases of high grade invasive carcinoma which underwent radical cystectomy only one out of nine cases showed positivity for FGFR3.

Guancial et al., did not find any association between muscle-invasive urothelial carcinoma and overall survival (18). Turo et al., also reported similar findings (26).

One of the cases in our study was diagnosed to have low grade non-invasive carcinoma who underwent radical cystectomy. Clinically and radiologically he had extensive involvement of the bladder mucosa by papillary neoplasm, with histopathological extension into the prostatic ducts. This case had an interesting FGFR3 staining pattern of nuclear positivity.

Nuclear positivity of FGFR3 has not been studied extensively due to the small proportion of such staining in other studies. In the study done by Rotterud et al., in 2007 (27), they concluded that nuclear positivity of FGFR3 led to the tumor genesis. In a Korean study done in 2010, nuclear FGFR3 positivity was reported in $32.7 \%$ of the tumors but it failed to show prognostic power (4).

\section{Conclusion}

The FGFR3 expression is seen in urothelial carcinoma. It is high in low grade, non-invasive tumors, and tumors showing recurrences which are non-invasive. The targeted therapy for FGFR3 may be used as one of the modes of treatment for urothelial carcinoma. It can also be used as a marker to determine the grade in difficult cases and the risk of recurrence.

\section{Acknowledgements}

We would like to thank Mr. Simon C Durairaj, research scholar in Department of Pathology Sri Ramachandra Medical College for helping with the application of IHC.

\section{Conflict of Interest}

The authors declare that there is no conflict of interest regarding the publication of this article. 


\section{References}

1. Jemal A, Eble JN, Sauter G, Epstein JI, Sesterhenn IA. Pathology and genetics of tumors of the urinary system and male genital organs. World Health Organization Classi. 2004.

2. Billerey C, Chopin D, Aubriot-Lorton M, Ricol D, Gil Diez de Medina S, Van Rhijn B et al. Frequent FGFR3 Mutations in Papillary Non-Invasive Bladder (pTa) Tumors.

Am J Pathol.2001; 158(6):1955-1959.

3. Tomlinson DC, Baldo O, Harnden P, Knowles MA. FGFR3 protein expression and its relationship to mutation status and prognostic variables in bladder cancer. J PATHOL. 2007; 213(1):91-8. https://doi.org/10.1002/path.2207

4. Maeng YH, Eun SY, Huh JS. Expression of fibroblast growth factor receptor 3 in the recurrence of non-muscleinvasive urothelial carcinoma of the bladder.Korean $\mathrm{J}$ Urol. 2010; 51(2):94-100. https://doi.org/10.4111/kju.2010.51.2.94

5. Lee HJ, Kang HJ, Kim KM, Yu ES, Kim KH, Kim SM, Kim TW, Shim JH, Lim YS, Lee HC, Chung YH. Fibroblast growth factor receptor isotype expression and its association with overall survival in patients with hepatocellular carcinoma. ClinMolHepatol. 2015 Mar;21(1):60.

https://doi.org/10.3350/cmh.2015.21.1.60

6. Lee H, Douglas-Jones AG, Morgan JM, Jasani B. The effect of fixation and processing on the sensitivity of oestrogen receptor assay by immunohistochemistry in breast carcinoma. J ClinPathol. 2002 Mar 1;55(3):236-8 https://doi.org/10.1136/jcp.55.3.236.

7. Rafique M, Javed AA. Clinico-pathological features of bladder carcinoma: experience from a tertiary care hospital of Pakistan.INT UROL NEPHROL. 2006;38(2):247-50.

https://doi.org/10.1007/s11255-006-6676-1

8. El Mawla NG, El Bolkainy MN, Khaled HM. Bladder cancer in Africa: update. SeminOncol 2001; 28(2):174178.

https://doi.org/10.1053/sonc.2001.21961

9. Poletajew S, Walędziak M, Fus Ł, Pomada P, Ciechańska J, Wasiutyński A. Urothelial bladder carcinoma in young patients is characterized by a relatively good prognosis.Ups J Med Sci. 2012;117(1):47-51. https://doi.org/10.3109/03009734.2011.650797

10. Huang H, Sun M, Li X, Jin J. Urothelial carcinoma of the bladder in patients aged 30 years or younger: clinicopathological analysis and expression of fibroblast growth factor receptor 3 (FGFR3) of 45 cases.Med Oncol. 2015 ; 32(5):137. https://doi.org/10.1007/s12032-015-0581-3

11. Mandhani A, Gupta P, Jain M, Kapoor R, Muruganandham K, Srivastava A. Impact of age and gender on the clinicopathological characteristics of bladder cancer. Indian J Urol. 2009; 25(2):207. https://doi.org/10.4103/0970-1591.52916

12. Biswas RR, Mangal S, Guha D, Basu K, Karmakar D. An epidemiological study of cases of urothelial carcinoma of urinary bladder in a tertiary care centre. J Krishna Institute of Med Sci. 2013; 2(1):82-.

13. Spruck CH, Rideout WM, Olumi AF, Ohneseit PF, Yang AS, Tsai YC et al. Distinct pattern of p53 mutations in bladder cancer: relationship to tobacco usage. Cancer Res. 1993; 53(5):1162-6.

14. Gómez-Román JJ, Saenz P, González JC, Escuredo K, Santa Cruz S, Junquera C et al. Fibroblast growth factor receptor 3 is overexpressed in urinary tract carcinomas and modulates the neoplastic cell growth. Clin Cancer Res. 2005; 11(2):459-65.

15. Poyet C, Hermanns T, Zhong Q, Drescher E, Eberli D, Burger $\mathrm{M}$ et al. Positive fibroblast growth factor receptor 3 immunoreactivity is associated with low-grade noninvasive urothelial bladder cancer. Oncol Lett. 2015; 10(5):2753-60. https://doi.org/10.3892/ol.2015.3691

16. Matsumoto M, Ohtsuki Y, Ochii K, Seike Y, Iseda N, Sasaki $\mathrm{T}$ et al. Fibroblast growth factor receptor 3 protein expression in urothelial carcinoma of the urinary bladder, exhibiting no association with low-grade and/or noninvasive lesions. Oncol Rep. 2004; 12(5):967-71. https://doi.org/10.3892/ol.2015.3691

17. Bodoor K, Ghabkari A, Jaradat Z, AlKhateeb A, Jaradat $\mathrm{S}$, Al-Ghazo MA et al. FGFR3 mutational status and protein expression in patients with bladder cancer in a Jordanian population. Cancer Epidemiol. 2010; 34(6):724-32.

https://doi.org/10.1016/j.canep.2010.05.003

18. Guancial EA, Werner L, Bellmunt J, Bamias A, Choueiri TK, Ross $\mathrm{R}$ et al. FGFR3 expression in primary and metastatic urothelial carcinoma of the bladder. Cancer Med. 2014; 3(4):835-44. https://doi.org/10.1002/cam4.262

19. Tavakkoly-Bazzaz J, Salami SA, Pourmand MR, Mansouri F, Mashahdi R, Pourmand G. Differential expression of FGFRs signaling pathway components in bladder cancer: A step toward personalized medicine. Balkan J Med Genet. 2017 Dec 29;20(2):75-81. https://doi.org/10.1515/bjmg-2017-0026

20. Kobayashi H, Kikuchi E, Mikami S, Maeda T, Tanaka N, Miyajima A, Nakagawa K, et al. Long term follow-up in patients with initially diagnosed low grade Ta non-muscle invasive bladder tumors: tumor recurrence and worsening progression. BMC urol. 2014; 14(1):5. https://doi.org/10.1186/1471-2490-14-5

21. Mhawech-Fauceglia P, Cheney RT, Fischer G, Beck A, Herrmann FR. FGFR3 and p53 protein expressions in patients with pTa and pT1 urothelial bladder cancer.Eur J SurgOncol. 2006; 32(2):231-7. https://doi.org/10.1016/j.ejso.2005.11.018 
22. vanOers JM, Wild PJ, Burger M, Denzinger S, Stoehr R, Rosskopf E et al. FGFR3 mutations and a normal CK20 staining pattern define low-grade noninvasive urothelial bladder tumors.Eur Urol. 2007; 52(3):760-8. https://doi.org/10.1016/j.eururo.2007.01.009

23. Ahmad F, Mahal V, Verma G, Bhatia S, Das BR. Molecular investigation of FGFR3 gene mutation and its correlation with clinicopathological findings in Indian bladder cancer patients. Cancer Rep.2018 ;1(3):e1130. https://doi.org/10.1002/cnr2.1130

24. . van Rhijn BW, Lurkin I, Radvanyi F, Kirkels WJ, van der Kwast TH, Zwarthoff EC. The fibroblast growth factor receptor 3 (FGFR3) mutation is a strong indicator of superficial bladder cancer with low recurrence rate. Cancer research. 2001 Feb 2;61(4):1265-8.

25. Hernández S, López-Knowles E, Lloreta J, Kogevinas M, Amorós A, TardónA et al. Prospective study of FGFR3 mutations as a prognostic factor in nonmuscle invasive urothelial bladder carcinomas. J ClinOncol. 2006; 24(22):3664-71.

https://doi.org/10.1200/JCO.2005.05.1771

26. Turo R, Harnden $P$, Thygesen $H$, Fleischmann A, Thalmann GN, Seiler R et al. FGFR3 expression in primary invasive bladder cancers and matched lymph node metastases. J Urol. 2015; 193(1):325-30. https://doi.org/10.1016/j.juro.2014.06.026

27. Rotterud R, Fossa SD, Nesland JM. Protein networking in bladder cancer: immunoreactivity for FGFR3, EGFR, ERBB2, KAI1, PTEN, and RAS in normal and malignant urothelium. HistolHistopathol. 2007; 22(4-6):349-64.

28. Burry RW. Controls for immunocytochemistry: an update. J HistochemCytochem 2011;59(1):6-12. https://doi.org/10.1369/jhc.2010.956920

\section{How to Cite This Article:}

Akanksha M, Sandhya S. Role of FGFR3 in Urothelial Carcinoma. Iranian Journal of Pathology. 2019; 14(2): 148-155. 